\title{
VALORIZAÇÃO DE DIETAS COM COQUETEL ENZIMÁTICO PARA TILÁPIAS DO NILO EM TEMPERATURA SUB-ÓTIMA
}

\author{
(Valorization of diets with enzymatic blend for Nile tilapias at sub-great temperature)
}

\author{
Veruska Dilyanne Silva Gomes ${ }^{1}$, José Humberto Vilar da Silva ${ }^{1}$, Alda Lúcia de Lima Amâncio ${ }^{1}$, José \\ Jordão Filho ${ }^{1}$, Cacio Ribeiro Cavalcanti ${ }^{1}$, Jorge Luiz dos Santos Almeida ${ }^{1}$ \\ ${ }^{1}$ Universidade Federal da Paraíba
}

Corresponding author: veruska_sgomes@yahoo.com.br

RESUMO: Temperaturas abaixo da zona de conforto (sub-ótimas) diminuem a atividade metabólica do organismo, o que pode ocasionar perdas no crescimento e desenvolvimento dos peixes. Melhorar a disponibilidade de nutrientes pode favorecer os índices produtivos. Objetivou-se com este trabalho, avaliar a suplementação com coquetel enzimático (200 ppm de fitase, 400 ppm de protease e 200ppm de alfa-amilase) em dietas com redução nutricional sobre desempenho e composição físico-química corporal de tilápias mantidas em temperatura sub-ótima $\left(23,15 \pm 0,2^{\circ} \mathrm{C}\right)$. O experimento foi conduzido na UFPB/CCHSA por um período de 60 dias. Foram utilizados 260 alevinos machos de tilápia do Nilo, pós-indução sexual, distribuídos em um delineamento inteiramente casualizado com quatro tratamentos e cinco repetições. Sendo DC (dieta controle), DCEE (dieta controle com coquetel enzimático), DV1EE (redução em 1,32\% de PB e ED + coquetel enzimático) e DV2EE (redução em 2,64\% de PB e ED + coquetel enzimático). Foram avaliados os parâmetros de desempenho e composição físico-química da carcaça. A suplementação enzimática foi eficiente em disponibilizar nutrientes suprindo um déficit de até $2,64 \%$ de energia e proteína na dieta das tilápias submetidas a temperaturas sub-ótima.

Palavras-chave: aditivos; enzimas; metabolismo.

ABSTRACT: Temperatures below the comfort zone (sub-optimal) decrease the metabolic activity of the organism, which can cause losses in fish growth and development. Improving the availability of nutrients can favor the productive indexes. The objective of this work was to evaluate the enzyme blend supplementation (200 ppm of phytase, 400 ppm of protease and 200 ppm of alpha-amylase) in diets with nutritional reduction on performance and physical and chemical composition of tilapia kept at sub-temperature $\left(23.15 \pm 0.2^{\circ} \mathrm{C}\right)$. The trial was conducted at the UFPB / CCHSA for a period of 60 days. A total of 260 male Nile tilapia fingerlings, sexually induced, were distributed in a completely randomized design with four treatments and five replicates. The control diet DCEE (control diet with enzyme blend), DV1EE (reduction of $1.32 \%$ of PB and ED + enzyme blend) and DV2EE (reduction of $2.64 \%$ of $\mathrm{PB}$ and ED + enzyme blend). The parameters of performance and physicochemical composition of the carcass were evaluated. The enzymatic supplementation was efficient in providing nutrients supplying a deficit of up to $2.64 \%$ of energy and protein in the diet of tilapia submitted to sub-optimal temperatures.

Keywords: additives; metabolism; enzymes.

Recebido em 28/06/2018

Aprovado em 10/07/2019 


\section{INTRODUÇÃO}

A qualidade da água tem importância primordial para a eficiência de um sistema de produção de organismos aquáticos. Estando intimamente relacionada com a saúde, funções fisiológicas, crescimento e aspectos qualitativos do pescado produzido (Cyrino et al., 2010).

Alguns sistemas de produção não permitem intervenção humana efetiva sobre os aspectos fisio-químicos da água. A qualidade da água em sistemas de produção em tanques-rede depende das características do corpo da água no qual está instalado (Boyd, 2010). Em viveiros escavados pode haver variações térmicas elevadas ao longo do dia (Mercante et al., 2007).

A maioria das espécies de peixes catalogadas são ectotérmicos, ou seja, tem sua temperatura corpórea diretamente regulada pela temperatura da água (Beitinger et al., 2000). No entanto, quando a temperatura não está na zona de conforto térmico do animal, este tende a priorizar a busca pela homeostase. Quando o estresse térmico é intenso ou duradouro, pode gerar respostas adaptativas que vão desde ajustes fisiológicos à imunossupressão e diminuição do crescimento e desenvolvimento dos peixes (Barton, 2002).

As tilápias são tolerantes a uma diversidade de fatores ambientais como mudanças no $\mathrm{pH}$, temperatura, concentração de oxigênio dissolvido na água e concentrações de amônia (Deen e Zaki, 2010). Mas, sobreviver em condições adversas não confere recursos para que a espécie expresse seu potencial genético em crescimento e desenvolvimento corporais.

Temperaturas abaixo ou no limite mínimo da zona de conforto térmico dos peixes, ou seja, temperaturas subótimas diminuem a atividade metabólica do organismo, fator que pode expressar menor consumo de ração, baixo ganho em peso, menor comprimento padrão e piora na conversão alimentar. Nesse contexto, a temperatura que possibilitou maior ganho em peso e melhor conversão alimentar de tilápias mantidas em quatro temperaturas (20, 24,28 e $32^{\circ} \mathrm{C}$ ) se manteve entre $28^{\circ} \mathrm{C}$ e $32^{\circ} \mathrm{C}$ (Moura et al., 2007).

$$
\text { A utilização de aditivos }
$$

enzimáticos nas rações para peixes mantidos em temperaturas dentro da zona de conforto térmico para a espécie, tem demonstrado resultados positivos quanto ao aumento do coeficiente de digestibilidade de rações formuladas com ingredientes que apresentam teor elevado de polissacarídeos não amiláceos para tilápias do Nilo (Tachibana et al., 2010), a redução de fatores antinutricionais em dietas para jundiá (Pretto et al. 2017), promove melhor conversão alimentar no híbrido tambacu (Martins et al., 2016) e aumenta o peso final e ganho em peso de juvenis de tilápia (Moura et al., 2012). A utilização de coquetéis enzimáticos contendo protease e amilase podem auxiliar as enzimas endógenas na digestão da proteína e amido presentes na ração viabilizando maior eficiência digestiva e, consequentemente, melhor absorção destes nutrientes. Guimarães et al., (2009) destacam que existe uma relação forte e positiva entre a inclusão de um complexo enzimático contendo protease e o aumento do coeficiente de digestibilidade aparente da proteína, atribuindo essa relação a uma maior interação enzima-substrato e a digestão eficiente de outros nutrientes como carboidratos e lipídios associados à disponibilidade da proteína na ração.

A adição de enzimas em dietas de animais aquáticos pode potencializar a digestão dos alimentos vegetais $e$, aumentar assim a disponibilidade dos nutrientes após a passagem do alimento 
pelo trato gastrointestinal e melhorar o desempenho de espécies onívoras como as tilápias do Nilo. Objetivou-se com este trabalho, avaliar a suplementação com coquetel enzimático composto por fitase, protease e amilase em dietas com redução nutricional sob o desempenho e composição físicoquímica corporal de tilápias do Nilo mantidas em temperatura sub-ótima.

\section{MATERIAL E MÉTODOS}

O experimento foi conduzido no Laboratório de Aquicultura do Centro de Ciências Humanas, Sociais e Agrárias CCHSA da Universidade Federal da Paraíba, Bananeiras - PB, por um período de 60 dias. Foram utilizados 260 alevinos machos de tilápia do Nilo, pós-indução sexual, com peso 1,12 \pm $0,002 \mathrm{~g}$, distribuídos em um delineamento inteiramente casualizado, com quatro tratamentos e cinco repetições. A instalação experimental é composta por um sistema de recirculação fechada, com filtro mecânico, biológico e aeração constante.

As dietas experimentais 1 (DC = dieta controle, sem adição de enzimas) e 2 (DCEE = dieta controle + coquetel enzimático) foram formuladas seguindo as recomendações de Furuya (2010), com $30 \%$ de proteína bruta (\%) e 3000 $\mathrm{kcal}$ de energia bruta/kg. A dieta valorizada 1 (DV1EE) foi formulada obedecendo uma redução proteica e energética de $1,32 \%$ e a dieta valorizada 2 (DV2EE) foi elaborada seguindo uma redução de $2,64 \%$ em relação a dieta referência (Tabela 1).

Para a confecção das dietas DCEE, DV1EE e DV2EE foi adicionado o coquetel enzimático formulado mediante associação de três enzimas inseridas nas seguintes proporções: 400ppm de protease, 200ppm de alfaamilase e 200ppm fitase. Os ingredientes foram triturados, pesados, misturados (misturador " $Y$ " USIBRAS $尺$ ), sendo as enzimas adicionadas, em substituição ao inerte. O processo para obtenção da ração farelada seguiu a metodologia descrita por Signor et al. (2013), posteriormente, as rações passaram pelo processo de peletização onde foi utilizanda a peletizadora CHAVANTE®. Todas as rações peletizadas permaneceram armazenadas sobre refrigeração durante todo o período experimental.

Os peixes foram alimentados quatro vezes por dia $(8: 00 \mathrm{~h} ; 11: 00 \mathrm{~h}$; 14:30h e 17:00h) seguindo uma taxa de arraçoamento de $10 \%$ da biomassa, obtida através de biometrias quinzenais. Após último fornecimento diário de ração, foi realizada a limpeza de resíduos sólidos e renovação de $5 \%$ da água no sistema. Diariamente, $\mathrm{o} \mathrm{pH}$, oxigênio dissolvido e temperatura foram monitorados com $O$ auxilio de peagâmetro (HANNA®) e Oxímetro/termômetro

Semanalmente foi quantificada a amônia total no sistema de recirculação.

Ao final do experimento as tilápias foram submetidas a 12 horas de jejum para esvaziamento completo do trato digestório, posteriormente, dez peixes por unidade experimental foram insensibilizados por imersão em gelo, abatidos, pesados e medidos para avaliação dos seguintes parâmetros: peso final; ganho em peso: GP = (peso final)-(peso inicial); $C R$ = Consumo de ração; Conversão alimentar: $\mathrm{CA}=$ (consumo de ração) $\div$ (ganho de peso); CTF = Comprimento total final (medido do focinho ao final da nadadeira caudal); GCT = Ganho em comprimento total; CPF = Comprimento padrão final (medido do focinho ao início da nadadeira caudal); GCF = Ganho em comprimento final; ALT = Altura ( medida à frente do $1^{\circ}$ raio da nadadeira dorsal); LAG = Largura (medida à frente 
do $1^{\circ}$ raio da nadadeira dorsal) e Taxa de crescimento específico $(T C E)=[((\operatorname{In}$ peso final - In peso inicial $) \div$ tempo) $x$ 100].

Tabela 1- Composição alimentar e nutricional das dietas experimentais

\begin{tabular}{|c|c|c|c|c|}
\hline \multirow{2}{*}{ Ingredientes (kg) } & \multicolumn{4}{|c|}{ Dietas experimentais (\%) $^{1}$} \\
\hline & $\mathrm{DC}$ & DCEE & DV1EE & DV2EE \\
\hline Farelo de soja $45 \%$ & 54,00 & 54,00 & 52,86 & 51,65 \\
\hline Milho & 37,00 & 37,00 & 38,44 & 40,26 \\
\hline Farinha de peixes $55 \%$ & 3,500 & 3,500 & 3,500 & 3,500 \\
\hline Fosfato bicálcico & 1,270 & 1,270 & 1,230 & 1,190 \\
\hline Óleo de soja & 1,250 & 1,250 & 0,745 & 0,140 \\
\hline Calcário & 1,840 & 1,840 & 2,080 & 2,120 \\
\hline Premix vitamínico e mineral $^{2}$ & 0,500 & 0,500 & 0,500 & 0,500 \\
\hline Sal & 0,300 & 0,300 & 0,300 & 0,300 \\
\hline Dl-metionina & 0,200 & 0,200 & 0,200 & 0,200 \\
\hline Vitamina C & 0,006 & 0,006 & 0,006 & 0,006 \\
\hline $\mathrm{BHT}$ & 0,020 & 0,020 & 0,020 & 0,020 \\
\hline Inerte & 0,100 & 0,020 & 0,020 & 0,020 \\
\hline Produto comercial Protease ${ }^{3}$ & - & 0,040 & 0,040 & 0,040 \\
\hline Produto comercial Fitase ${ }^{4}$ & - & 0,020 & 0,020 & 0,020 \\
\hline \multirow[t]{2}{*}{ Produto comercial Alfa-amilase $^{b}$} & - & 0,020 & 0,020 & 0,020 \\
\hline & 100,0 & 100,0 & 100,0 & 100,0 \\
\hline \multicolumn{5}{|l|}{ COMPOSIÇÃO NUTRICIONAL (\%) } \\
\hline Energia digestível (Mcal/Kg) & 3.036 & 3.036 & 2.9960 & 2.9560 \\
\hline Proteína bruta & 30,00 & 30,00 & 29,60 & 29,20 \\
\hline Matéria seca & 89,07 & 89,07 & 89,01 & 88,92 \\
\hline Cálcio & 1,100 & 1,100 & 1,500 & 1,500 \\
\hline Cinzas & 7,880 & 7,880 & 8,510 & 8,470 \\
\hline Fosforo total & 1,060 & 1,060 & 0,760 & 0,750 \\
\hline Lisina total & 1,880 & 1,880 & 1,850 & 1,820 \\
\hline Metionina total & 0,520 & 0,520 & 0,630 & 0,630 \\
\hline Sódio & 0,190 & 0,190 & 0,190 & 0,190 \\
\hline Treonina total & 1,180 & 1,180 & 1,120 & 1,130 \\
\hline Vitamina C (mg/Kg) & 0,060 & 0,060 & 0,060 & 0,060 \\
\hline \multicolumn{5}{|c|}{ 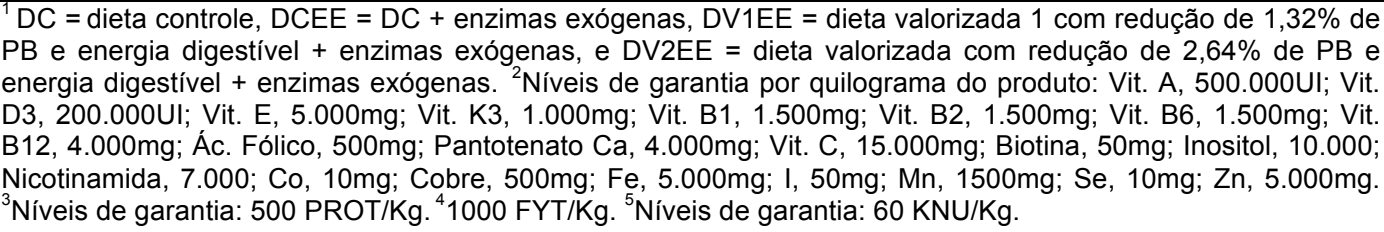 } \\
\hline
\end{tabular}

Para avaliação físico-química, cinco peixes inteiros foram triturados e homogeneizados gerando uma amostra composta por unidade experimental. A composição das tilápias foi obtida utilizando-se a metodologia descrita pela Association of Official Analytical Chemistry - AOAC (2000), sendo 
realizadas em triplicata ao teor de umidade (\%), cinzas (\%), lipídeos totais (\%) e proteína bruta (\%).

Os dados obtidos foram analisados pelo teste $\mathrm{F} e$, em caso de diferenças significativas as médias dos tratamentos foram comparadas pelo teste de Duncan $(P<0,05)$.

\section{RESULTADOS E DISCUSÃO}

Os valores médios de $\mathrm{pH}$, oxigênio dissolvido, amônia total foram, respectivamente, 7,32 $\pm 0,28 ; 7,036 \pm$ 0,22 (mg/L); 0,625 $\pm 0,37$ (ppm); permanecendo dentro da faixa aceitável para o bom desempenho da espécie, segundo recomendações de Kubitza
(2004). A temperatura média, 23,15 \pm 0,22 permaneceu abaixo ou no limiar mínimo da zona de conforto térmico para peixes tropicais. Durante o período experimental (sessenta dias) não foram observadas mortes.

Os parâmetros de desempenho não foram influenciados pela redução nutricional ou pela adição do coquetel enzimático (Tabela 2). $O$ peso final variou entre $13,70 \mathrm{~g}$ e $14,31 \mathrm{~g}$; o ganho em peso variou entre $13,18 \mathrm{~g}$ nas tilápias alimentadas com a dieta DCEE e 12,58g para as que receberam dieta sem inclusão das enzimas (DC). O consumo de ração permaneceu entre $25,04 \mathrm{~g}$ e 23,98g.

Tabela 2 - Peso inicial (PI), peso final (PF), ganho em peso (GP), consumo de ração (CR), conversão alimentar (CA) e taxa de crescimento específico (TCE) de juvenis de tilápia do Nilo alimentadas com dietas contendo enzimas exógenas ${ }^{1}$.

\begin{tabular}{lcccccc}
\hline Dietas $^{2}$ & PI $(\mathrm{g})$ & PF $(\mathrm{g})$ & GP $(\mathrm{g})$ & CR $(\mathrm{g})$ & $\mathrm{CA}(\mathrm{g})$ & TCE $(\% /$ dia $)$ \\
\hline DC & $1,116^{\mathrm{a}}$ & $13,705^{\mathrm{a}}$ & $12,588^{\mathrm{a}}$ & $23,98^{\mathrm{a}}$ & $1,90^{\mathrm{a}}$ & $4,17^{\mathrm{a}}$ \\
DCEE & $1,123^{\mathrm{a}}$ & $14,312^{\mathrm{a}}$ & $13,189^{\mathrm{a}}$ & $25,04^{\mathrm{a}}$ & $1,89^{\mathrm{a}}$ & $4,24^{\mathrm{a}}$ \\
DV1EE & $1,125^{\mathrm{a}}$ & $13,898^{\mathrm{a}}$ & $12,773^{\mathrm{a}}$ & $24,32^{\mathrm{a}}$ & $1,90^{\mathrm{a}}$ & $4,18^{\mathrm{a}}$ \\
DV2EE & $1,134^{\mathrm{a}}$ & $13,800^{\mathrm{a}}$ & $12,675^{\mathrm{a}}$ & $24,16^{\mathrm{a}}$ & $1,91^{\mathrm{a}}$ & $4,16^{\mathrm{a}}$ \\
\hline CV(\%) & 2,23 & 4,12 & 4,49 & 4,12 & 1,42 & 1,90
\end{tabular}

${ }^{1}$ Médias na mesma coluna seguidas de letras distintas diferem $(\mathrm{P} \leq 0,05)$ pelo teste de Duncan. ${ }^{2} \mathrm{DC}=$ dieta controle, $\mathrm{DCEE}=$ $\mathrm{DC}+$ coquetel enzimático, DV1EE = dieta valorizada com redução de $1,32 \%$ de PB e energia digestível + coquetel enzimático, e DV2EE = dieta valorizada com redução de $2,64 \%$ de PB e energia digestível + coquetel enzimático.

A conversão alimentar em todos os

tratamentos permaneceu acima do esperado para a espécie em sistema de produção intensivo, onde a única fonte de alimento disponível é a ração. A taxa de crescimento específico não foi influenciada pela redução nutricional quando as dietas foram suplementadas com protease, fitase e amilase, no entanto, estão abaixo dos obtidos para tilápias do Nilo mantidas em temperaturas dentro da zono de conforto térmico para a espécie.

O efeito obtido para os parâmetros de desempenho avaliados pode indicar que, mesmo em baixas temperaturas, a suplementação enzimática foi eficiente em melhorar a disponibilidade dos nutrientes das dietas DV1EE e DV2EE.
Moura et al. (2012) em experimento avaliando a eficiência de um complexo enzimático SFF composto por protease, fitase, lipase e carboidrases sob parâmetros de desempenho de tilápias do Nilo mantidas em condições ótimas de temperatura da água $\left(28^{\circ} \mathrm{C}\right)$, obtiveram melhor conversão alimentar (variando entre 1,11 e 1,23) quando comparadas as obtidas no presente estudo.

As enzimas digestivas são específicas quanto ao $\mathrm{pH}$, substrato no qual atuam (PRETTO et al., 2017) e temperatura (SILVA et al., 2017). A eficiência digestiva das enzimas, tanto de produção endógena quanto as adicionadas de forma unitária, em coquetéis ou complexos enzimáticos em 
rações para tilápias, pode diminuir quando sua especificidade não é respeitada.

Moura et al. (2007), ao avaliarem o desempenho e atividade enzimática da amilase em tilápias do Nilo submetidas a quatro condições de temperatura, sendo $20,24,28$ e $32^{\circ} \mathrm{C}$ durante 55 dias, constataram que o consumo de ração, peso final e ganho em peso diminuíram linearmente com a diminuição da temperatura da água. As tilápias mantidas em ambiente com temperatura média de $20^{\circ} \mathrm{C}$ ganharam $2,30 \mathrm{~g}$ de peso, em contrapartida, as que permaneceram em ambiente com $32^{\circ} \mathrm{C}$ de temperatura ganharam em média 47,75g. A atividade da amilase apresentou efeito linear, diminuindo conforme a temperatura diminuiu, demostrando que a temperatura do meio interfere na velocidade das reações catalisadas pela enzima.

As medidas morfométicas, comprimento total final e ganho em comprimento total, não foram influencias pela suplementação enzimática ou pela redução energética e proteica com adição do coquetel de protease, amilase e fitase (tabela 3).

Tabela 3 - Comprimento total final (CTF), ganho em comprimento total (GCT), comprimento padrão final (CPF), altura final (AF), ganho em altura (GA), largura final (LAF) e ganho em largura (GLA) de juvenis de tilápia do Nilo alimentadas com dietas contendo enzimas exógenas ${ }^{1}$.

\begin{tabular}{|c|c|c|c|c|c|c|c|}
\hline Dietas $^{2}$ & CTF $(\mathrm{cm})$ & $\begin{array}{l}\text { GCT } \\
(\mathrm{cm})\end{array}$ & $\begin{array}{l}\text { CPF } \\
(\mathrm{cm})\end{array}$ & $\begin{array}{c}\text { AF } \\
(\mathrm{cm})\end{array}$ & $\begin{array}{c}\text { GA } \\
(\mathrm{cm})\end{array}$ & LAF (cm) & GLA (cm) \\
\hline DC & $8,63^{a}$ & $5,18^{a}$ & $6,81^{b}$ & $2,35^{a}$ & $1,50^{a}$ & $1,022^{a}$ & $0,722^{a}$ \\
\hline DCEE & $8,74^{a}$ & $5,29^{a}$ & $6,99^{a}$ & $2,38^{a}$ & $1,53^{a}$ & $1,038^{a}$ & $0,738^{a}$ \\
\hline DV1EE & $8,74^{a}$ & $5,29^{a}$ & $6,90^{\mathrm{ab}}$ & $2,28^{a}$ & $1,43^{a}$ & $1,014^{a}$ & $0,714^{a}$ \\
\hline DV2EE & $8,73^{a}$ & $5,28^{a}$ & $6,89^{a b}$ & $2,29^{a}$ & $1,44^{a}$ & $1,000^{a}$ & $0,700^{a}$ \\
\hline $\mathrm{CV}(\%)$ & 1,60 & 2,66 & 1,73 & 3,70 & 5,82 & 3,03 & 4,29 \\
\hline
\end{tabular}

Quando as dietas sem redução nutricional foram comparadas, as tilápias que receberam a dieta DCEE (com adição enzimática) apresentaram maior comprimento padrão final $(6,99 \mathrm{~cm})$, enquanto as tilápias que foram alimentadas com a dieta controle estavam medindo em média $6,81 \mathrm{~cm}$. Entre as dietas com suplementação enzimática, não houve diferença para o parâmetro avaliado. O mesmo ocorreu entre as dietas DV1EE, DV2EE e a dieta DC ("on top" sem adição do coquetel enzimático).

Os paramentos altura final $(\mathrm{cm})$, ganho em altura final $(\mathrm{cm})$, largura final e ganho em largura não foram influenciados $\quad(p<0,05) \quad$ pela suplementação enzimática com ou sem redução nutricional. Apesar da inclusão de enzimas, aparentemente possibilitar maior disponibilidade de nutrientes para absorção pelos peixes, visto que, as reduções energéticas e proteicas não influenciaram as medida morfométricas. Em temperatura sub-ótima, as tilápias apresentaram crescimento reduzido.

Massago et al. (2010), avaliando o crescimento de quatro linhagens de tilápia do Nilo durante 112 dias, em temperatura de $26^{\circ} \mathrm{C}$, obtiveram resultados para comprimento padrão aos 56 dias superiores aos apresentados pelas tilápias do presente estudo. De acordo com a linhagem, o comprimento padrão permaneceu entre $8,57 \mathrm{~cm}$ (linhagem Bouaké) a 9,46cm (linhagem Supreme).

O ganho em comprimento padrão (Figura 1) não apresentou efeito 
significativo para os tratamentos valorizados com o coquetel enzimático, com ou sem reduções nutricionais (CV\% 2,87 ). Quando as dietas "on top" foram comparadas, a suplementação enzimática foi eficiente em melhorar 0 ganho em comprimento padrão, onde as tilápias alimentadas com a dieta DCEE obtiveram $4,24 \mathrm{~cm}$ e as que receberam a dieta DC mediram $4,06 \mathrm{~cm}$.

A suplementação com as enzimas fitase, protease e amilase pode promover uma rápida disponibilidade de nutrientes essenciais para a formação do esqueleto, musculatura e tecido de reserva. No entanto, as porcentagens de umidade, cinzas, lipídeos totais e proteína bruta dos juvenis de tilápia não sofreram alterações significativas $(p<0,05)$ mediante inclusão do coquetel enzimático e redução ou não de nutrientes da dieta (Tabela 4).

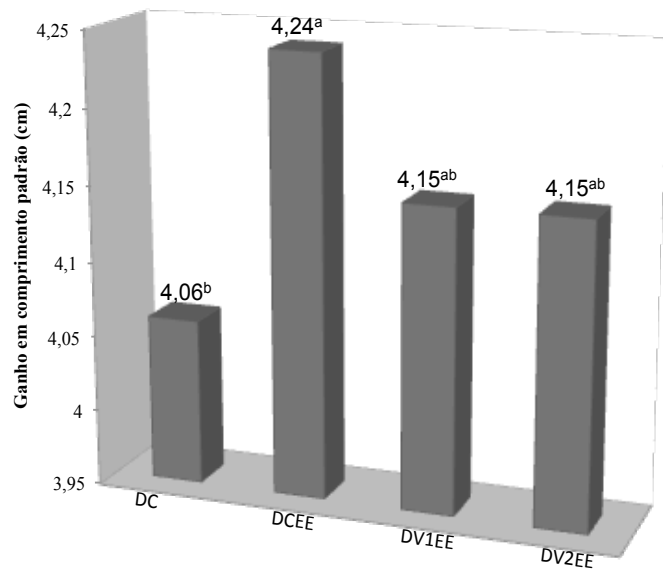

Figura 1 - Ganho em comprimento padrão (cm) de tilápias do Nilo, alimentadas com dietas valorizadas com coquetel enzimático.

Tabela 4 - Composição físico-química de juvenis de tilápia do Nilo alimentadas com dietas contendo enzimas exógenas ${ }^{1}$.

\begin{tabular}{lcccc}
\hline Dietas $^{2}$ & Umidade (\%) & Cinzas (\%) & Lipídeos totais (\%) & $\begin{array}{c}\text { Proteína bruta } \\
(\%)\end{array}$ \\
\hline DC & $75,27^{\mathrm{a}}$ & $9,75^{\mathrm{a}}$ & $38,17^{\mathrm{a}}$ & $55,2^{\mathrm{a}}$ \\
DCEE & $75,17^{\mathrm{a}}$ & $9,60^{\mathrm{a}}$ & $40,65^{\mathrm{a}}$ & $57,34^{\mathrm{a}}$ \\
DV1EE & $76,77^{\mathrm{a}}$ & $9,89^{\mathrm{a}}$ & $39,18^{\mathrm{a}}$ & $56,00^{\mathrm{a}}$ \\
DV2EE & $75,66^{\mathrm{a}}$ & $10,17^{\mathrm{a}}$ & $38,66^{\mathrm{a}}$ & $57,89^{\mathrm{a}}$ \\
\hline \multicolumn{1}{c}{ CV(\%) } & 2,10 & 5,35 & 3,81 & 3,45 \\
\hline
\end{tabular}

${ }^{1}$ Médias na mesma coluna seguidas de letras distintas diferem $(P \leq 0,05)$ pelo teste de Duncan. ${ }^{2} \mathrm{DC}=$ dieta controle, DCEE = DC + coquetel enzimático,DV1EE = dieta valorizada 1 com redução de $1,32 \%$ de PB e energia digestível + coquetel enzimático, e DV2EE = dieta valorizada com redução de $2,64 \%$ de $\mathrm{PB}$ e energia digestível + coquetel enzimático.

Os resultados obtidos corroboram os achados de Adeoye et al. (2016), que ao avaliar a suplementação unitária de fitase, protease e carboidrases em dietas para tilápia do Nilo, não encontraram diferenças para umidade, lipídeos e cinzas do animal inteiro

Em outras espécies onívoras como o peixe Kinguio, Signor et al. (2013) não observaram influencia de enzimas exógenas na composição corporal do animal inteiro. Signor et al. (2010), avaliando a eficiência de um complexo enzimático (composto por amilase, protease, celulase, lipase, pectinase, xilanase, $\beta$-glucanase e fitase) sobre o desempenho de tilápias do Nilo mantidas em temperatura média de $24,5^{\circ} \mathrm{C}$, não observaram diferenças para umidade, proteína bruta e material mineral na carcaça.

\section{CONCLUSÃO}

A suplementação de dietas com níveis de $2,64 \%$ de PB e ED abaixo da exigência com 400ppm de protease, $200 \mathrm{ppm}$ de alfa-amilase e 200ppm de fitase não afeta o desempenho das 
tilápias mantidas em temperatura média sub-ótima de $23^{\circ} \mathrm{C}$ para a espécie.

\section{AGRADECIMENTOS}

A Coordenação de Aperfeiçoamento de Pessoal de Nível Superior (CAPES), a empresa DSM e a empresa Guaraves/Aquavita pelo fornecimento de recursos para a realização deste trabalho.

\section{NOTAS INFORMATIVAS}

Este estudo faz parte de um projeto que foi submetido para avaliação do Comitê de Ética no uso de animais da Universidade Federal da Paraíba (CEUA-UFPB), sendo aprovado com o protocolo $n^{\circ}$ 057/2016.

\section{REFERÊNCIAS}

ADEOYE, A. A., JARAMILLO-TORRES, A., FOX, S. W. et al. Supplementation of formulated diets for tilapia (Oreochromis niloticus) with selected exogenous enzymes: Overall performance and effects on intestinal histology and microbiota. Animal Feed Science and Technology, v. 215, p. 133-143, 2016.

BARTON, B. A. Stress in fishes: a diversity of responses with particular reference to changes in circulating corticosteroids. Integrative and comparative biology, v. 42 , n. 3 , p. 517-525, 2002.

BEITINGER, T. L.; BENNETT, W. A.; MCCAULEY, R. W. Temperature tolerances of North American freshwater fishes exposed to dynamic changes in temperature. Environmental biology of fishes, v. 58, n. 3, p. 237-275, 2000.

BOYD, C. E. Cage design, placement affect water quality. Global Aquaculture Advocate, v. 13, n 3, p. 21-22, 2010.
CYRINO, J. E. P.; BICUDO, A. J. A.; SADO, R. Y. et al. A piscicultura e o ambiente - 0 uso de alimentos ambientalmente corretos em piscicultura. Revista Brasileira de Zootecnia, v.39, p.68-87, 2010.

DEEN, A. I. E. N., ZAKI, M. Impact of climatic change (oxygen and temperature) on growth and survival rate of Nile Tilapia (Oreochromis niloticus). Report and Opinion, v. 2, p. 192-195, 2010.

FURUYA, W. M. Tabelas Brasileiras para a Nutrição de Tilápias. Toledo: GFM. 100p. 2010.

GUIMARÃES, I. G.; FALCON, D. R.; $\mathrm{SCHICH}$, D. et al. Digestibilidade aparente de rações contendo complexo enzimático para tilápia-do-nilo. Arquivo Brasileiro de Medicina Veterinária e Zootecnia, v.61, n.6, p.1397-1402, 2009.

MARTINS, M. G., MOURA, G. M., FERREIRA, T. A. et al. Inclusão de complexo enzimático ssf em rações para juvenis de tambacu. Archives of Veterinary Science, v. 21, n. 1, 2016.

MASSAGO, H., CASTAGNOLLI, N., MALHEIROS, E. B. et al. Crescimento de quatro linhagens de tilápia Oreochromis niloticus. Revista Acadêmica: Ciência Animal, v. 8, n. 4, 2010.

MERCANTE, C. T. J., MARTINS, Y. K., CARMO, C. F. et al. Qualidade da água em viveiro de Tilápia do Nilo (Oreochromis niloticus): caracterização diurna de variáveis físicas, químicas e biológicas, São Paulo, Brasil. Bioikos, v. 21, n. 2, 2007.

MOURA, G. S., OLIVEIRA, M. G. A., LANNA, E. T. A. et al. Desempenho e atividade de amilase em tilápias-do-nilo submetidas a diferentes temperaturas. Pesquisa Agropecuária Brasileira, 42(11), 1609-1615. 2007. 
MOURA, G.S.; LANNA, E.A.T.; FILER, $K$. et al. Effects of enzyme complex SSF (solid state fermentation) in pellet diets for Nile tilapia. Revista Brasileira de Zootecnia. v.41, n.10, p.2139-2143, 2012

PRETTO, A., DA SILVA, L. P., DA VEIGA, M. L. et al. Tratamento enzimático em farelo de crambe e aplicação em dietas para Rhamdia quelen. Caderno de Ciências Agrárias, v. 9, n. 1, p. 62-74, 2017.

SIGNOR, A. A.; BOSCOLO, W.R.; BITTENCOURT, F. et al. Desempenho de juvenis de Tilápia-do-nilo alimentados com rações contendo complexo enzimático. Revista Brasileira de Zootecnia, v.39, n.5, p.977-983, 2010.

SIGNOR, A.A.; LUCHESI, J.D.; COSTA, J.M. et al. Complexo enzimático na dieta de alevinos de kinguio (Carassius auratus). Semina: Ciências Agrárias, Londrina, v. 34 , n. 3 , p. 1381-1388, 2013.

SILVA, E. T. L. D., PEDREIRA, M. M., DIAS, M. L. F. et al. Larvas de linhagens de tilápia do Nilo submetidas à frequências alimentares sob baixa temperatura. Revista Brasileira de Saúde e Produção Animal, v. 18, n. 1, p. 193-203, 2017.

TACHIBANA, L.; PINTO, L. G. Q.; GONÇALVES, G. S. et al. Xilanase e $\beta$ glucanase na digestibilidade aparente de nutrientes do triticale pela Tilápia-donilo. Arquivo Brasileiro de Medicina Veterinária e Zootecnia, v.62, n.2, p.445-452, 2010. 